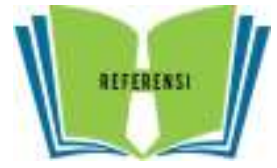

\title{
PENGARUH INOVASI PRODUK TERHADAP KINERJA PEMASARAN INDUSTRI MEBEL DI KABUPATEN PASURUAN
}

\author{
Akhmad Nasir \\ Economics College of Gempol \\ annaz_putra@vahoo.co.id
}

\begin{abstract}
Marketing strategies expected by the company is the way to increase the number of product sales according to the target. Strategies arranged by the company are directed to result performance, especially marketing performance. In a large company, product innovation has become a continuous marketing strategy based on the need in order to maintain marketing performance, but how about the small and medium scale company such as Furniture Company which still has a limited understanding of marketing strategies. For the small and medium scale company, product innovation might become an important aspect for the viability of the company. The total of samples at Furniture Company in Pasuruan Regency is 38 respondents. Data are analysed by using simple regression analysis. Product innovation might influence marketing performance. Therefore, company is supposed to maintain the quality of product which has been trusted by the consumers.
\end{abstract}

Keywords: Product Innovation, Marketing Performance, Marketing Strategies

\section{Abstrak}

Strategi pemasaran yang diharapkan perusahaan adalah bagaimana untuk meningkatkan jumlah penjualan produk sesuai target. Strategi yang dibuat oleh perusahaan diarahkan untuk menghasilkan kinerja, terutama kinerja pemasaran. Pada perusahaan besar inovasi produk sudah menjadi strategi pasar yang berkelanjutan sesuai kebutuhan guna mempertahankan kinerja pemasaran, namun bagaimana bagi perusahaan kecil dan menengah seperti industri mebel yang masih memiliki keterbatasan pemahaman terhadap strategi pemasaran. Bagi perusahaan kecil dan menengah apakah inovasi produk merupakan hal yang penting bagi kelangsungan bisnis secara berkelanjutan. Sampel penelitian ini pada perusahaan mebel di Kabupaten Pasuruan yang berjumlah 38 responden. Teknik analisis data yang digunakan peneliti adalah analisis regresi sederhana. Inovasi pada produk berpengaruh terhadap kinerja pemasaran, untuk itu perusahaan ditekankan untuk menjaga kualitas produk yang sudah dipercaya konsumen.

Kata kunci : Inovasi Produk, Kinerja Pemasaran, Strategi Pemasaran 


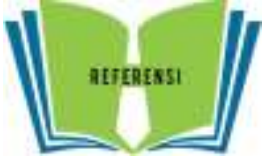

ISSN: 2089-0532, e-ISSN: 2548-6152

\section{PENDAHULUAN}

Persaingan pasar yang semakin ketat menuntut perusahaan untuk memiliki strategi pemasaran yang tepat dalam menghadapi pesaing. Apabila perusahaan tidak dapat bertahan dalam bersaing maka dapat dipastikan perusahaan tersebut akan mengalami kerugian. Dalam bersaing strategi pemasaran memiliki peran penting untuk bisa terhindar dari kerugian. Strategi pemasaran yang diharapkan perusahaan adalah bagaimana untuk meningkatkan jumlah penjualan produk sesuai target.

\section{Strategi yang dibuat oleh perusahaan diarahkan untuk menghasilkan kinerja, terutama kinerja pemasaran. Dalam perusahaan kinerja pemasaran penting untuk dicapai karena kinerja pemasaran merupakan prestasi yang diperoleh perusahaan dalam mencapai target penjualan di pasar dengan strategi tertentu, tidak hanya penjualan tetapi porsi pasar juga harus diperhatikan. Ferdinand (2000) menyatakan bahwa kinerja pemasaran dapat dikatakan baik mencakup tiga besaran utama, yaitu nilai penjualannya, pertumbuhan penjualan dan porsi dalam pasar, yang pada akhirnya dapat menambah keuntungan perusahaan.}

\footnotetext{
Kesuksesan jangka panjang bisnis yang diharapkan sebuah perusahaan adalah ketika bisnis dalam sebuah perusahaan mampu memberikan nilai manfaat kepada pelanggan secara berkelanjutan. Untuk memberikan nilai manfaat secara berkelanjutan adalah dengan mempertahankan kinerja pemasaran perusahaan secara berkelanjutan (Astrid, 2010). Fokus perusahaan dalam jangka panjang dilakukan secara bertahap untuk meningkatan kinerja pemasaran dan upaya peningkatan daya saing
}

perusahaan dapat dilakukan dengan cara memfokuskan pada kebutuhan pasar.

Kondisi pasar akan mengalami perubahan artinya dinamika pemasaran berdampak pada perubahan selera pelanggan. Perubahan pasar seperti ini menuntut perusahaan untuk melakukan inovasi pada produk agar dalam rangka mempertahankan kelangsungan hidup dan memperoleh keuntungan perusahaan (Tjiptono, 2008). Inovasi harus dilakukan secara berkelanjutan oleh perusahaan karena sudah merupakan kebutuhan mendasar agar mampu menciptakan keunggulan produk dalam bersaing. Upaya untuk melakukan inovasi produk merupakan fungsi penting dari pihak manajemen suatu perusahaan karena inovasi produk dapat menentukan suatu kinerja pemasaran yang berkualitas. Inovasi akan semakin bertambah penting sebagai satu alat untuk kelangsungan hidup, bukan hanya pertumbuhan tetapi juga dalam persaingan yang semakin hebat dan ketidak pastian lingkungan (Wahyono, 2002).

Pada perusahaan besar inovasi produk sudah menjadi strategi pasar yang berkelanjutan sesuai kebutuhan guna mempertahankan kinerja pemasaran, namun bagaimana bagi perusahaan kecil dan menengah seperti industri mebel yang masih memiliki keterbatasan pemahaman terhadap strategi pemasaran. Bagi perusahaan kecil dan menengah apakah inovasi produk merupakan hal yang penting bagi kelangsungan bisnis secara berkelanjutan. Untuk itu peneliti menguji pengaruh inovasi produk terhadap kinerja pemasaran industri mebel di Kabupaten Pasuruan. 


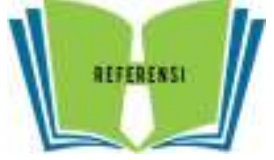

ISSN: 2089-0532, e-ISSN: 2548-6152

\section{TINJAUAN PUSTAKA}

\section{Strategi Pemasaran}

Pemasaran adalah kegiatan seseorang yang diarahkan untuk pemenuhan kebutuhan dan memuaskan kebutuhan serta pemenuhan keinginan melalui proses pertukaran (Assauri, 2004). Untuk memenuhi kebutuhan dan keinginan seorang individu perusahaan perlu memfasilitasi dengan strategi pemasaran. Strategi pemasaran menurut Kotler, dkk (2010) adalah strategi yang dapat memposisikan perusahaan secara kuat dalam menghadapi pesaing dan memberikan keunggulan strategis terkuat bagi perusahaan. Penting bagi perusahaan untuk memiliki strategi pemasaran yang kuat, upaya ini diharapkan dapat mempertahankan posisi bisnis perusahaan dalam bersaing. Dampak yang terjadi apabila perusahaan tidak memiliki strategi pemasaran yang kuat adalah penurunan volume penjualan secara terus menerus yang berakibat pada pailit atau bangkrut.

\section{Inovasi Produk}

Tjiptono (2008) menyatakan bahwa inovasi merupakan penerapan secara praktis sebuah gagasan ke dalam suatu produk atau proses baru. Inovasi adalah kondisi pada barang dan jasa bahkan gagasan yang dianggap sebagai sesuatu yang baru (Kotler dan Keller, 2007). Inovasi yang dilakukan pada produk sangat diperlukan dengan tujuan untuk mempertahankan minat beli konsumen. Inovasi produk yang dilakukan secara efektif dengan intensitas yang tinggi dapat menentukan kinerja pemasaran dalam sebuah perusahaan. Suendro (2010) bahwa inovasi produk yang semakin tinggi akan mempengaruhi kinerja pemasaran dan selanjutnya meningkatkan keunggulan bersaing berkelanjutan.

\section{Kinerja Pemasaran}

Kinerja adalah hasil kerja secara kualitas dan kuantitas yang dicapai oleh seseorang pegawai dalam melaksanakan tugasnya sesuai dengan tanggung jawab yang diberikan kepadanya (Mangkunegara, 2009). Dalam aplikasinya upaya tersebut menjadi satu kebutuhan untuk dilakukan dalam mengoptimalkan kinerja usaha. Market orientation memiliki peran yang sama penting dan dapat memberikan kontribusi terhadap peningkatan kinerja perusahaan (Hatani, 2000).

\section{Gambar 1 \\ Kerangka Pemikiran}

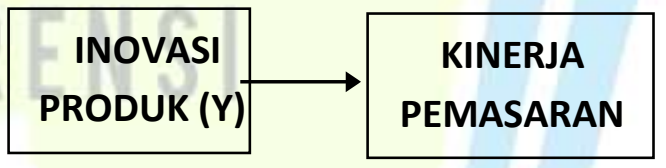

\section{Hipotesis Penelitian}

Inovasi produk sangat penting dilakukan oleh sebuah perusahaan dengan tujuan untuk mempertahankan nilai manfaat produk bagi konsumen. Nilai manfaat yang dirasakan oleh konsumen adalah terpenuhinya kebutuhan yang diinginkan konsumen oleh produk tersebut. Inovasi produk yang secara terus menerus dapat meningkatkan kinerja pemasaran. Kinerja pemasaran dapat ditingkatkan melalui keunggulan bersaing dimana keunggulan bersaing dapat tercipta dengan melakukan inovasi produk (Kusumo,2006). 


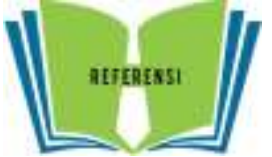

ISSN: 2089-0532, e-ISSN: 2548-6152

$\mathrm{H}_{0}$ : tidak ada pengaruh signifikan inovasi produk terhadap kinerja pemasaran

$\mathrm{H}_{\mathrm{a}}$ : ada pengaruh signifikan inovasi produk terhadap kinerja pemasaran

\section{METODE PENELITIAN \\ Desain Penelitian}

Penelitian ini meneliti adanya hubungan sebab akibat antara variabel inovasi produk dengan kinerja pemasaran. Untuk mengetahui kinerja pemasaran perusahaan maka peneliti menilai ari variabel inovasi produk yang dipilih dalam penelitian ini. Desain penelitian kausalitas adalah desain penelitian yang disusun untuk meneliti kemungkinan adanya hubungan sebab akibat antarvariabel (Sanusi, 2011).

\section{Variabel Penelitian}

Sebab akibat adalah desain penelitian yang digunakan dalam penelitian ini maka variabel yang terlibat dalam penelitian ini terdiri dari variabel bebas yaitu; inovasi produk (X) dan variabel terikat yaitu; kinerja pemasaran (Y).

\section{Metode Pengumpulan Data}

Informasi yang ingin diperoleh peneliti berupa tanggapan dari responden yang berkaitan dengan inovasi produk yang dilakukan perusahaan dan kinerja pemasaran yang diinginkan perusahaan, maka jenis data kualitatif yang berasal dari responden berupa tanggapan, akan tetapi dikuantifikasi dengan cara pemberian skor (Sanusi,2011). Sumber data yang diperoleh secara langsung dari responden dengan tujuan untuk mengontrol tentang kausalitas data, peneliti dapat mengatasi kesenjangan waktu antara saat data dibutuhkan dengan ketersediaan data tersebut. Untuk memperoleh data, peneliti menggunakan teknik pengumpulan data kuesioner yang disampaikan langsung oleh peneliti kepada responden dan menggunakan teknologi komputer atau via email.

\section{Instrumen Penelitian}

Instrumen penelitian dikenal dengan alat untuk mengumpulkan data. Untuk memperoleh data yang mempunyai tingkat akurasi dan konsistensi yang tinggi, maka instrumen penelitian yang digunakan harus valid dan reliabel. Untuk mengetahui valid dan reliabel tidaknya instrumen maka dilakukan pengujian secara validitas dan secara reliabilitas.

\section{Tabel 1 Instrumen Penelitian}

\begin{tabular}{|c|l|l|l|}
\hline No & \multicolumn{1}{|c|}{ Variabel } & Indikator & \multicolumn{1}{c|}{ Sub Indikator } \\
\hline 1 & Inovasi Produk & - Inovasi teknis & - Desain \\
& & - Inovasi adm/ & - Desain harga \\
& & perubahan desain & \\
\hline 2 & Kinerja & - Pertumbuhan & - Target \\
& Pemasaran & penjualan & penjualan yang \\
& & - Pertumbuhan & diharapkan \\
& & pasar & - Pertumbuhan \\
& & - Pertumbuhan & $\begin{array}{l}\text { penjualanyang } \\
\text { dicapai }\end{array}$ \\
& & & $\begin{array}{l}\text { - Perluasan pangsa } \\
\text { pasar }\end{array}$ \\
\hline
\end{tabular}

Populasi dan Sampel Penelitian

Industri mebel terletak di 4 Kecamatan dengan jumah industri mebel secara keseluruhan sebanyak 38 perusahaan. Berdasarkan jumlah data perusahaan mebel maka besarnya jumlah populasi yang juga merupakan sampel dalam penelitian ini adalah berjumlah 38 responden.

\section{Teknik Analisis Data Uji Regresi Sederhana}

Alat analisis yang digunakan adalah analisis regresi sederhana 
merupakan analisis yang berupa satu variabel terikat/tergantung yang diberi simbol Y dan variabel kedua yang berupa variabel bebas diberi simbol $\mathrm{X}$ (Sanusi, 2011). Analisis regresi berganda dapat dinyatakan dengan persamaan berikut:

$$
Y=a+b X
$$

Keterangan.

$\mathrm{Y}=$ Nilai prediksi dari variabel $\mathrm{Y}$ berdasarkan Nilai Variabel X

$\mathrm{a}=$ titik potong $\mathrm{Y}$;merupakan nilai bagi $\mathrm{Y}$ ketika $\mathrm{X}=0$

$\mathrm{b}=$ Slope (perkiraan besarnya perubahan nilai variabel $\mathrm{Y}$ bila nilai variabel $\mathrm{X}$ berubah satu unit pengukuran)

$\mathrm{X}=$ nilai variabel $\mathrm{X}$ yang dipilih

\section{Uji Hipotesis}

Menguji signifikansi koefisien regresi linier secara parsial yang berkaitan dengan pernyataan hipotesis penelitian. Kriteria yang digunakan peneliti dalam pengambilan keputusan sebagai berikut.

Jika $-\mathrm{t}_{\text {tabel }} \leq \mathrm{t}_{\text {hitung }} \leq \mathrm{t}_{\text {tabel }}$; maka

$\mathrm{H}_{0}$ diterima

$\mathrm{t}$ hitung $<\mathrm{t}$ tabel atau $\mathrm{t}$ hitung $>$

$\mathrm{t}$ tabel; $\mathrm{H} 0$ di tolak maka $\mathrm{H}_{\mathrm{a}}$ diterima

\section{Uji Koefisien Determinasi (R2)}

Nilai koefisien determinasi (R2) adalah antara nol dan satu. Nilai R2 yang kecil berarti kemampuan variabel inovasi produk dalam menjelaskan variasi variabel kinerja pemasaran amat terbatas. Nilai yang mendekati satu berarti variabel inovasi produk memberikan hampir semua informasi yang dibutuhkan untuk memprediksi variasi variabel kinerja pemasaran (Ghozali, 2009).

\section{HASIL DAN PEMBAHASAN PENELITIAN}

Hasil Uji Validitas

Tabel 2 Hasil Uji Validitas

\begin{tabular}{|c|c|c|c|}
\hline Indikator & $\begin{array}{l}\text { Item } \\
\text { Pertanyaan }\end{array}$ & $\begin{array}{l}\text { Korelasi } \\
(\mathbf{r})\end{array}$ & Keterangan \\
\hline \multirow[t]{3}{*}{ Inovasi teknis } & 1 & 0,957 & Valid \\
\hline & 2 & 0,895 & Valid \\
\hline & 3 & 0,903 & Valid \\
\hline \multirow{3}{*}{$\begin{array}{l}\text { Inovasi adm/ } \\
\text { perubahan desain }\end{array}$} & 4 & 0,705 & Valid \\
\hline & 5 & 0,864 & Valid \\
\hline & 6 & 0,898 & Valid \\
\hline \multirow{2}{*}{$\begin{array}{l}\text { Pertumbuhan } \\
\text { penjualan }\end{array}$} & 1 & 0,898 & Valid \\
\hline & 2 & 0,952 & Valid \\
\hline \multirow[t]{2}{*}{ Pertumbuhan pasar } & 3 & 0,975 & Valid \\
\hline & 4 & 0,957 & Valid \\
\hline Pertumbuhan laba & 5 & 0,985 & Valid \\
\hline
\end{tabular}

Sumber : Olah data SPSS, 2017

Pengujian validitas yang dilakukan pada instrumen penelitian menunjukkan bahwa besarnya nilai korelasi nyatakan valid. Artinya instrumen yang digunakan untuk mengumpulkan data dapat dinilai keabsahannya atau reliabel.

\section{Hasil Uji Reliabelitas}

Tabel 3

Hasil Uji Reliabelitas Reliability Statistics

\begin{tabular}{|c|c|}
\hline $\begin{array}{c}\text { Cronbach's } \\
\text { Alpha }\end{array}$ & N of Items \\
\hline, 876 & 11 \\
\hline
\end{tabular}

Sumber : Olah data SPSS, 2017

Pengujian instrumen penelitian secara reliabelitas dengan tujuan untuk mengetahui kehandalan instrumen 


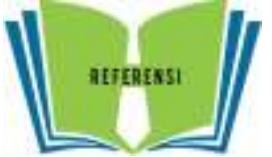

ISSN: 2089-0532, e-ISSN: 2548-6152

penelitian dalam pengumpulan data. Berdasarkan tabel hasil uji reliabelitas menunjukkan bahwa besarnya nilai Cronbach's Alpha adalah 0,876. Instrumen dinyatakan handal karena lebih besar dari 0,6 (Ghozali, 2009).

\section{Hasil Uji Regresi Sederhana Tabel 4 \\ Hasil Uji Regresi Sederhana}

\begin{tabular}{|c|c|c|c|c|c|c|c|}
\hline \multirow{2}{*}{ Model } & \multicolumn{2}{|c|}{$\begin{array}{c}\text { Unstandardized } \\
\text { Coefficients }\end{array}$} & $\begin{array}{c}\text { Standardiz } \\
\text { ed } \\
\text { Coefficient } \\
\mathrm{s}\end{array}$ & \multirow{2}{*}{$\mathrm{t}$} & \multirow{2}{*}{ Sig. } & \multicolumn{2}{|c|}{$\begin{array}{c}\text { Collinearity } \\
\text { Statistics }\end{array}$} \\
\cline { 2 - 5 } & $\mathrm{B}$ & Std. Error & Bet a & & & Tolerance & VIF \\
\hline $\begin{array}{c}1 \text { (Constant) } \\
\text { Inovasi } \\
\text { Produk }\end{array}$ & 1,120 & $\begin{array}{c}7,796 \\
, 189\end{array}$ &, 665 & 5,913 &, 000 &, 997 & 1,00 \\
1
\end{tabular}

a. Dependent Variable: Kinerja Pemasaran

Sumber : Olah data SPSS, 2017

Hasil regresi sederhana diperoleh koefisien untuk variabel inovasi produk sebesar 1,120 dengan besarnya konstanta 5,106, maka dapat ditentukan model persamaan regresi berikut ini.

$$
Y=5,106+1,120 X
$$

\section{Hasil Uji Hipotesis}

Koefisien regresi untuk variabel inovasi produk sebesar 0,665. Koefisien ini signifikan pada $\alpha=0,05$ dengan nilai t hitung 5,913 > 2,042. Dapat dinyatakan bahwa $\mathrm{H}_{0}$ di tolak maka $\mathrm{H}_{\mathrm{a}}$ diterima, artinya ada pengaruh signifikan inovasi produk terhadap kinerja pemasaran perusahaan mebel di Kabupaten Pasuruan. Penting bagi perusahaan mebel di Kabupaten Pasuruan untuk terus melakukan inovasi produk dengan cara inovasi teknis dan perubahan desain pada produk dengan tujuan untuk menjaga kinerja pemasaran perusahaan yang sudah ada dan kemudian meningkatkannya.

\section{Hasil Uji Koefisien Determinasi (R2)}

Tabel 5

Hasil Uji Koefisien Determinasi (R2)

Model Summary ${ }^{b}$

\begin{tabular}{|c|c|c|c|c|c|}
\hline Model & $\mathrm{R}$ & $\begin{array}{c}\mathrm{R} \\
\text { Square }\end{array}$ & $\begin{array}{c}\text { Adjusted } \\
\text { R Square }\end{array}$ & $\begin{array}{c}\text { Std. Error of } \\
\text { the Estimate }\end{array}$ & $\begin{array}{c}\text { Durbin- } \\
\text { Watson }\end{array}$ \\
\hline 1 &, $747 \mathrm{a}$ &, 558 &, 533 & 4,17396 & 2,147 \\
\hline
\end{tabular}

Sumber : Olah data SPSS, 2017

Besarnya nilai $R$ Square pada tabel hasil uji koefisien determinasi (R) adalah 0,558 , artinya besarnya variabel inovasi produk dalam menjelaskan variabel kinerja pemasaran sebesar $55,8 \%$ dan sisanya sebesar 44,2\% dijelaskan oleh variabel lain.

\section{KESIMPULAN DAN SARAN}

\section{Kesimpulan}

Inovasi pada produk berpengaruh terhadap kinerja pemasaran, untuk itu perusahaan ditekankan untuk menjaga kualitas produk yang sudah dipercaya konsumen, selain itu perusahaan dituntut untuk melakukan inovasi pada produk.

\section{Saran}

Dalam penelitian ini berdasarkan hasil uji koefisien determinasi (R) kinerja pemasaran tidak hanya ditentukan oleh inovasi produk, oleh karena itu disarankan kepada peneliti selanjutnya untuk menilai kinerja pemasaran perusahaan dari variabel bebas lainnya.

\section{DAFTAR PUSTAKA}

Ferdinand, A.T., (2000), Manajemen

Pemasaran: Sebuah

Pendekatan Stratejik, Badan

Penerbit Universitas

Diponegoro. Semarang. 


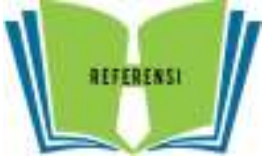

ISSN: 2089-0532, e-ISSN: 2548-6152

Astrid, Orsini Depary, (2010), "Analisis Faktor- Faktor Yang Mempengaruhi Kinerja Pemasaran Di Stasiun Pengisian Bahan Bakar Untuk Umum (SPBU) Semarang, Tesis, Dipublikasikan, Program Pascarsarjana Universitas Diponegoro, Semarang.

Wahyono. 2002. "Orientasi Pasar dan Inovasi : Pengaruhnya Terhadap Kinerja Pemasaran (Studi Kasus Pada Industri Mebel di Kabupaten Jepara)". Jurnal Sains Pemasaran Indonesia Vol. I No. 1 Hal : 23- 40.

Tjiptono, Fandy. 2008. Pemasaran Strategik. Penerbit : Andi Offset. Yogyakarta.

Kotler, Philip dan Gary Armstrong, (2010), Principles of Marketing, 13th Edition, Pearson Education, New Jersey.

Assauri, Sofyan. 2004. Manajemen Pemasaran. PT Raja Grafindi Persada, Jakarta.

Kotler, Philip dan Kevin Lare Keller. 2009. Manajemen Pemasaran, edisi tiga belas. Jilid 1 dan 2. Diterjemahkan oleh Benyamin Molan, Jakarta: Indeks.

Suendro, Ginanjar. 2010. Analisis pengaruh inovasi produk melalui kinerja pemasaran untuk mencapai keunggulan bersaing berkelanjutan. Semarang

Mangkunegara. Anwar Prabu. 2010. Evaluasi Kinerja Sumber Daya Manusia. Refika Aditama.

Hatani, La. 2000. "Pengaruh Orientasi Pasar Terhadap Kinerja Pemasaran di Kabupaten Muna”. Jurnal Manajemen Unhalu.

Kusumo, Agung Raharjo Wibowo. 2006. Analisis Faktor-Faktor yang Mempengaruhi inovasi produk untuk meningkatkan keunggulan bersaing dan kinerja pemasaran. Program studi magister manajemen. Program pasca sarjana. Universitas Diponegoro. Semarang.

Sanusi, Anwar. 2011. Metodologi Penelitian Bisnis. Penerbit Salemba Empat. Jakarta.

Ghozali, Imam.2009. Aplikasi analisi multivariat dengan program SPSS. BP-Undip. 